\title{
Characterization by length heterogeneity (LH)-PCR of a hydrogen-producing community obtained in dark fermentation using coastal lake sediment as an inoculum
}

\author{
Rita Di Bonito ${ }^{1 *}$, Antonella Marone ${ }^{2}$, Giulia Massini², Chiara Patriarca², Silvia Rosa², Antonella Signorini², \\ Cristiano Varrone ${ }^{2}$, Corinna Viola ${ }^{1}$ and Giulio Izzo ${ }^{2}$
}

\begin{abstract}
Background: Sustainable biohydrogen production can be achieved by dark fermentation of organic wastes, and studies were carried out using a range of substrates and inocula. The bacterial populations involved were mainly identified as facultative anaerobes (Enterobacteriaceae) and strictly anaerobes (Clostridiales), and their dynamics in relation to $\mathrm{H}_{2}$ and metabolite production depends on the physical and environmental conditions of the bioreactor. This study has evaluated the use of length heterogeneity $(L H)-P C R$ fingerprinting to detect changes in the microbial community during continuous hydrogen production under dark fermentation.
\end{abstract}

Methods: A mesophilic continuous dark fermentation was established using coastal lake sediment as an inoculum in a synthetic medium with glucose as a substrate. The LH-PCR profiling associated to the sequencing of 16S rRNA genes was used for the characterization of the bacterial community and identification of species during a continuous production of $\mathrm{H}_{2}$.

Results: The resulting dominant units of the communities present at both $24 \mathrm{~h}$ (batch) and $210 \mathrm{~h}$ (continuous culture) were affiliated to species of the genus Clostridium. Fluctuations based on their relative abundance over time were observed. At $24 \mathrm{~h}$, a higher ratio was detected for the group Clostridium butyricum - Clostridium tertium followed by Clostridium bifermentans and Clostridium perfringens, while at $210 \mathrm{~h}$, the group Clostridium aurantibutyricum - Clostridium acetobutylicum was the most abundant.

Conclusions: The LH-PCR profiling has proven to be a sensitive and rapid method for the evaluation of the dynamics of a functional consortium formed by species of the genus Clostridium and has a potential for studies aimed at the optimization of biohydrogen production.

Keywords: Biohydrogen, Dark anaerobic fermentation, Clostridium, $16 \mathrm{~S}$ rRNA genes, Length heterogeneity-PCR fingerprinting

\section{Background}

Biohydrogen can be obtained by dark fermentation of carbohydrates under both thermophilic and mesophilic conditions, and the exploitation of this process for the production of an environmentally friendly energy source could also reduce the dependence on fossil fuels [1].

\footnotetext{
* Correspondence: rita.dibonito@enea.it

'UTEE-AGR, National Agency for New Technologies, Energy and Sustainable Economic Development (ENEA), via Anguillarese 301, Rome 00123, Italy Full list of author information is available at the end of the article
}

Mesophilic fermentation has shown an interesting $\mathrm{H}_{2}$ production rate and seems to be promising for its economic feasibility [2], but the application of this process still needs improvement. Studies for the enhancement of the yield and the production rate have evaluated the effect of $\mathrm{pH}$, temperature, bioreactor design, and substrates [3-5], as well as the use of inocula made of pure cultures or artificial consortia [6,7]. In order to increase the sustainability of the process, experiments have been conducted using wastewater or organic wastes as 
substrates $[8,9]$. Slurry and other environmental matrices have also been selected and used as inocula since they are rich in $\mathrm{H}_{2}$ producers [3,4,7-9]. The members of bacterial communities during $\mathrm{H}_{2}$ production were mainly identified as facultative anaerobes, belonging to the Enterobacteriaceae and several species of the strict anaerobe Clostridium [1]. The structure and dynamics of communities using different substrates in relation to $\mathrm{H}_{2}$ and metabolite production were investigated using denaturant gradient gel electrophoresis (DGGE) of the $16 \mathrm{~S}$ rRNA gene $[10,11]$, and more recently, the capillary electrophoresis single-strand conformation of the 16S rRNA and Fe hydrogenase (hydA) genes of Clostridiales has been proposed [12].

The objective of this study was to develop a sensitive method for the evaluation of microbial community dynamics during continuous $\mathrm{H}_{2}$ production in a model dark fermentation. The data presented are part of a large experiment aimed at the selection and enrichment of a microbial consortium pool for biohydrogen production using a coastal lake sediment as an inoculum and testing different organic loads and retention times. The evaluation of metabolites during the process is not reported in this paper.

\section{Methods}

\section{Experiment}

A dark fermentation was established in a continuously stirred tank reactor of $2.5 \mathrm{l}$ with $1 \mathrm{l}$ of working volume and a synthetic basal fermentation medium [13], $\mathrm{pH} 6.7$, buffer $0.1 \mathrm{M}$ with $10 \mathrm{~g} \mathrm{l}^{-1}$ of glucose as a sole carbon source, and inoculated with $5 \mathrm{~g}$ of sediment. The sediment was manually collected from the coastal lake Fogliano, near Mar Tirreno (Central Italy), at a depth of about $1 \mathrm{~m}$ and stored at $-20^{\circ} \mathrm{C}$ for 9 months until use. The sampling area is characterized by anoxic conditions even a few millimeters below the water surface [14]. The tank reactor with the medium was sterilized before use, and all the operations were conducted under sterile conditions in order to evaluate the sediment community only. The reactor was sealed and sparged with $\mathrm{N}_{2}$ to establish anaerobic conditions. A constant temperature of $37^{\circ} \mathrm{C}$ and continuous mixing were obtained in a heating plate equipped with an aluminum jacket. The reactor operated for $24 \mathrm{~h}$ in batch mode to avoid the washing out of the microbial pool. Then, a continuous feeding was established by tubes connected to peristaltic pumps. The hydraulic retention time was set to $24 \mathrm{~h}$ during the first 3 days of operation and was then changed to $12 \mathrm{~h}$. The reactor was connected to a water displacement system in order to measure the biogas production, and the $\mathrm{H}_{2}$ content was evaluated by a gas chromatograph (Focus GC, Thermo Scientific, West Palm Beach, FL, USA) equipped with a thermal conductivity detector and a 3-m stainless steel column packed with Hayesep Q (800/100 mesh; Valco Instruments Co. Inc., Houston, TX, USA). Metabolite production and physical parameters as well as the amount of gas produced and its composition were evaluated several times daily. The reactor was operated continuously, and the cell viability was periodically determined using the Live/Dead ${ }^{\circledR}$ Bacterial Viability Kit, purchased from Molecular Probes Inc., Eugene, OR, USA, with five replications [15].

\section{Community characterization}

DNA was extracted from frozen sediment and pellets of the bioreactor cultures using the Fast DNA Spin Kit for Soil (QBiogene, Vista, CA, USA) and a modified protocol. Samples were mixed to $978 \mu \mathrm{l}$ of sodium phosphate buffer and $122 \mu \mathrm{l}$ of MT buffer, shaken with a vortex for $30 \mathrm{~s}$, incubated for $5 \mathrm{~min}$ at $65^{\circ} \mathrm{C}$, and centrifuged for $1 \mathrm{~min}$ at $10,000 \times g$. The supernatant was processed according to the manufacturer, and the DNA samples were used for LHPCR of the 16S rRNA V1 + V2 domains with the primer pair 27 F-6-FAM (fluorescently labelled) and 355R, as has been reported earlier [16]. The fragments were separated using the $\mathrm{ABI}$ Prism ${ }^{\circledR} 3730$ genetic analyzer (PE Biosystems, Foster City, CA, USA) under the setting Microsatellite, and the results were obtained by means of the software ABI Prism GeneMapper ${ }^{\circledR}$ V 4.0 that provided the evaluation of the size (bp) and the intensity for each amplicon of a given electropherogram, with respect to the internal ROX standard, using a minimum noise threshold of 50 fluorescent units. The analysis was conducted on replicate DNA extractions for each sample with two replicate LH-PCR profiles each. Binning and normalization were performed according to Mills et al. [16] in order to eliminate errors related to the data collection and analysis software. Thus, for each group of replicates, only fragments detected in three fourth of the profiles and relative ratios greater than $1 \%$ were considered reproducible and included in the analysis. The relative ratio for each amplicon was evaluated by dividing the peak height by the total intensity of the electropherogram, and the mean relative ratios were evaluated. Cloning and sequencing of the amplified 16S rRNA genes were performed according to [16], and the sequences were identified with respect to the NCBI GenBank database, using the MegaBLAST search option. LH-PCR was performed on the DNA from the clones, and the amplicon size was recorded as previously described. In addition, the cloned sequences were aligned with ClustalX [17] to the primers used for LH-PCR, and the virtual size of the corresponding fragments was evaluated (in silico analysis). The nucleotide sequences generated in this study were deposited in NCBI GenBank with the accession numbers: [GenBank:JX012104JX012128]. 


\section{Results and discussion}

Fingerprints of the bacterial communities were obtained at 24 and $210 \mathrm{~h}$ that respectively represented the beginning of the continuous phase and the time corresponding to a well-established continuous $\mathrm{H}_{2}$ production that reached an average of $50 \%$ of the total gas produced. At two times of sampling, the average yields were 240 and $238 \mathrm{ml} \mathrm{H}_{2} \mathrm{~g}^{-1}$, and the culture densities were $6.73 \times 10^{8}$ and $1.99 \times 10^{9}$ viable cells $/ \mathrm{ml}$, respectively. The community profiles are illustrated in Figure 1A and presented five distinct $\mathrm{LH}$ amplicons for both times of sampling indicated with letters corresponding to the sizes (bp): $a$ (330 to 331), $b$ (334), $c$ (336 to 337), $d$ (343 to 344 ), and $e$ (346 to 348). The average relative ratio of each amplicon was given in the ordinate and indicated not only the presence of the main community members at both times of sampling but also the fluctuations of their relative abundance. In fact, at $24 \mathrm{~h}$, amplicon $d$ was dominant followed by $a$ and $e$ with relative ratios of $41.13 \%, 22.9 \%$, and $20.3 \%$, respectively, while at $210 \mathrm{~h}$, amplicon $c$ was dominant (38.22\%) followed by $e$ and $d(27.96 \%$ and $12.46 \%$, respectively). The dominant units during the fermentation were also detected in the fingerprinting of the frozen sediment used as an inoculum (Figure 1B) with a different ratio. Two units present in the sediment profiles were not detected in the fermentation communities as expected when considering the selective stringent conditions of the process. All the cloned sequences were affiliated to species of the genus Clostridium. Table 1 shows the list of GenBank accessions presenting the higher identities. The LH-PCR performed on cloned sequences produced a single amplicon for each clone that matched one of the $a$ to $e$ community units. The size of LH amplicon of clones was confirmed by the virtual in silico analysis and allowed the identification of the community units as reported in Table 1 . Therefore, clones affiliated to Clostridium butyricum and Clostridium tertium were associated to amplicon $d$ dominant at $24 \mathrm{~h}$, while clones with identity to Clostridium aurantibutyricum and

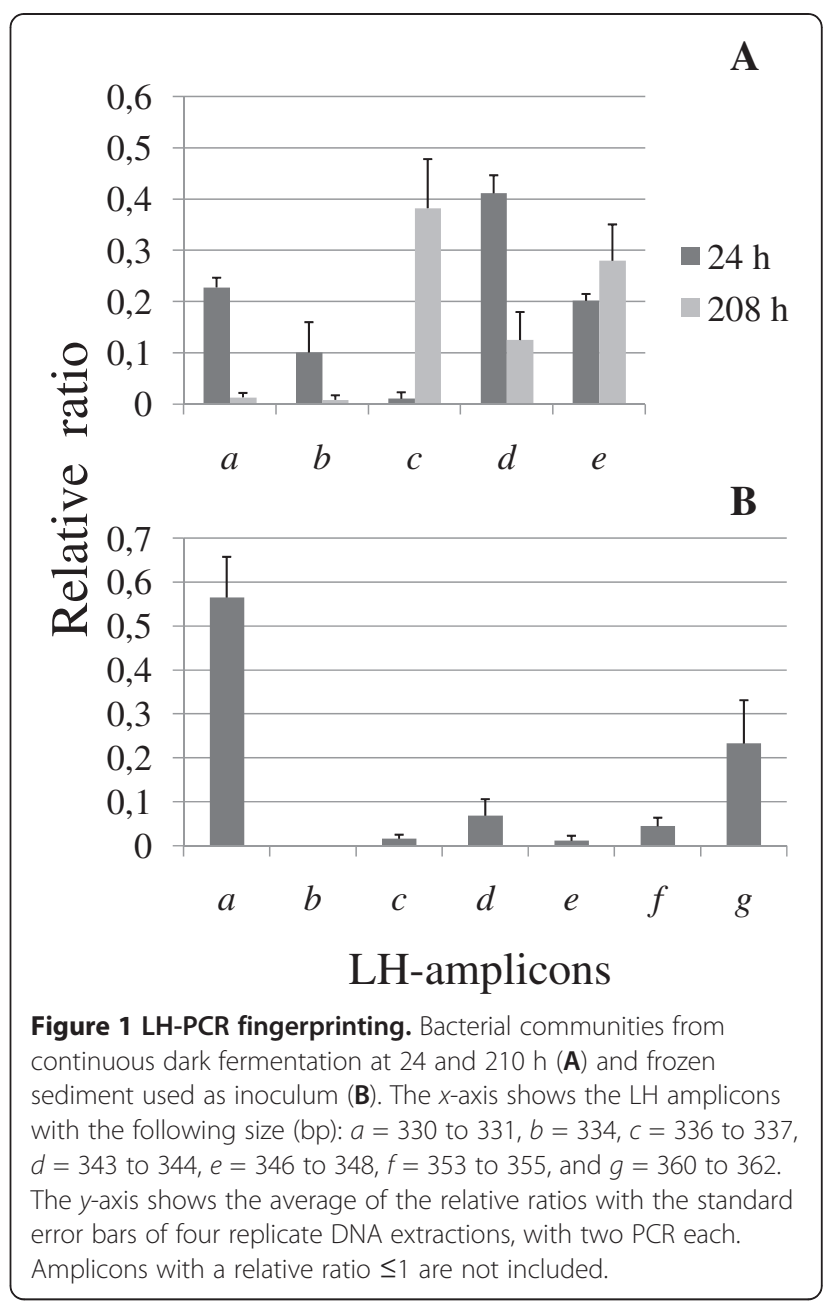

Clostridium acetobutylicum matched amplicon $c$ dominant at $210 \mathrm{~h}$. Clones affiliated to Clostridium bifermentans, Clostridium ghonii, and Clostridium perfringens presented the fragment sizes corresponding to amplicons $a, b$, and $e$, respectively. Most community studies on biohydrogen production have used the denaturing gradient gel electrophoresis (DGGE) profiling and evaluated the diversity as

Table 1 Affiliation of the 16S rRNA cloned sequences to accessions reported in the GenBank

\begin{tabular}{|c|c|c|c|c|}
\hline Number of clones & Time (h) & GenBank affiliation [accession no.] & Identity (\%) & LH amplicon \\
\hline 3,2 & 0,24 & C. bifermentans [GenBank:AB618787] & 98 to 100 & $a$ \\
\hline 1 & 24 & C. bifermentans [GenBank:AB538434] & 99 & $a$ \\
\hline 2 & 24 & C. ghonii [GenBank:AB542933] & 98 & $b$ \\
\hline 2,5 & 24,210 & C. aurantibutyricum [GenBank:FJ358641] & 96 & c \\
\hline 2 & 24 & C. acetobutylicum [GenBank:AB595131] & 96 & $c$ \\
\hline 3 & 24 & C. butyricum [GenBank:AB595129] & 99 to 100 & $d$ \\
\hline 1 & 24 & C. tertium [GenBank:AB618789] & 99 & $d$ \\
\hline 1 & 24 & C. perfringens [GenBank:AB627081] & 97 & e \\
\hline 1 & 24 & C. perfringens [GenBank:EU728702] & 98 & $e$ \\
\hline
\end{tabular}

The sequences were obtained from frozen sediment (time 0 ) and mesophilic continuous dark fermentation cultures after 24 and $210 \mathrm{~h}$. The association to the community profiling (amplicons $a$ to $e$ ) obtained by LH-PCR of clones is given. 
the presence/absence of bands on gels or the detection of the intensity using densitometric methods that still require visual evaluation [18]. The faint bands on DGGE gels are of difficult evaluation and often ignored $[3,10,18,19]$, while sequencing of the intense bands has sometimes revealed the presence of more than one species [10]. In this study, the ABI collection software allowed the distinction of amplicons differing in size of only a few base pairs and the accurate detection of the relative ratio for each of them, including the less abundant amplicons. The LH-PCR profiling is reported as a fast, reliable, and sensitive method for community studies in environmental samples, biological processes, and bioreactors, where diversity is present on the class/phylum level [16,20-22]. In this study, the taxonomic identification of community members as species of Clostridium is based on a limited number of clones that may not represent the whole community. However, all the amplicons during the process are associated to one or two of the clones that could represent the dominant units. Several studies have described communities mainly formed by Clostridia in dark fermentations started by pre-heated inoculum rich in spore-forming hydrogen producers $[11,12,18]$. In our work, the sediment was frozen until use since we had evidence from previous experiments that such treatment did not significantly affect the survival of $\mathrm{H}_{2}$-producing populations, allowing the storage of inoculum for serial experiments. Thus, the freezing and the strict control of anaerobiosis may have selected the Clostridium species. Although the data presented cannot distinguish the $\mathrm{H}_{2}$ producers from the other community members, the literature reported $\mathrm{H}_{2}$ production for strains of C. butyricum, C. bifermentans, and C. acetobutylicum in pure cultures [23-25] and C. perfringens in complex communities in bioreactors [11].

\section{Conclusions}

The inoculum allowed for establishing a mesophilic dark fermentation, and a microbial pool able to produce $\mathrm{H}_{2}$ was obtained. The method LH-PCR was reported for the first time in this type of process and proved to be effective for profiling a community formed by Clostridia. Moreover, the ABI collection software allowed the evaluation of community fluctuation based not only on the presence or the absence but also on the relative abundance of each unit, indicating the feasibility of the method for the evaluation of subtle changes in studies aimed at the biohydrogen production using the selected microbial pool.

\section{Competing interests}

The authors declare that they have no competing interests.

\section{Authors' contributions}

RDB carried out the molecular studies and drafted the manuscript. AM, GM $\mathrm{CP}, \mathrm{SR}, \mathrm{AS}$, and CrV carried out the anaerobic fermentations, the evaluation of metabolites, and the cell count. CoV helped in the analysis of molecular data and sequencing. Gl coordinated the study and its design. All the authors helped in the revision of the manuscript and approved the final version.

\section{Acknowledgments}

We thank the Genechron Facility at ENEA Casaccia Research Centre for the conduction of the sequencing and fragment analysis.

\section{Author details}

'UTEE-AGR, National Agency for New Technologies, Energy and Sustainable Economic Development (ENEA), via Anguillarese 301, Rome 00123, Italy. ${ }^{2}$ UTRINN-BIO, National Agency for New Technologies, Energy and Sustainable Economic Development (ENEA), via Anguillarese 301, Rome 00123, Italy.

Received: 12 February 2013 Accepted: 14 February 2013

Published: 28 February 2013

\section{References}

1. Lee DJ, Show KY, Su A (2011) Dark fermentation on biohydrogen production: pure culture. Biores Technol 102:8393-8402

2. Wu SY, Hung CH, Lin CN, Chen HW, Lee AS, Chang JS (2006) Fermentative hydrogen production and bacterial community structure in high-rate anaerobic bioreactors containing silicone-immobilized and self-flocculated sludge. Biotechnol Bioeng 93:934-946

3. Ueno Y, Haruta S, Ishii M, Igarashi Y (2001) Microbial community in anaerobic hydrogen-producing microflora enriched from sludge compost. Appl Microbiol Biotechnol 57:555-562

4. Kotsopoulos TA, Fotidis IA, Tsolakis N, Martzopoulos GG (2009) Biohydrogen production from pig slurry in a CSTR reactor system with mixed cultures under hyper-thermophilic temperature $\left(70^{\circ} \mathrm{C}\right)$. Biomass Bioen 33:1168-1174

5. Infantes D, Gonzales Del Campo A, Villaseñor J, Fernández FJ (2011) Influence of $\mathrm{pH}$, temperature and volatile fatty acids on hydrogen production by acidogenic fermentation. Int J Hydrogen Energy 36:15595-15601

6. Antonopoulou G, Ntaikou I, Gavala HN, Skidas IV, Angelopoulos K, Lyberatos $\mathrm{G}$ (2007) Biohydrogen production from sweet sorghum biomass using mixed acidogenic cultures and pure cultures of Ruminococcus albus. Global Nest J 9:144-151

7. Varrone C, Giussani B, Izzo G, Massini G, Marone A, Signorini A, Wang A (2012) Statistical optimization of biohydrogen and ethanol production from crude glycerol by microbial mixed culture. Int J Hydrogen Energy 37:16479-16488

8. Marone A, Massini G, Patriarca C, Signorini A, Varrone C, Izzo G (2012) Hydrogen production from vegetable waste by bioaugmentation of indigenous fermentative communities. Int J Hydrogen Energy 37:5612-5622

9. Varrone C, Rosa S, Fiocchetti F, Giussani B, Izzo G, Massini G, Marone A, Signorini A, Wang A (2013) Enrichment of activated sludge for enhanced hydrogen production from crude glycerol. Int J Hydrogen Energy 38:1319-1331

10. Ren N, Xing D, Rittman BE, Zhao L, Xie T, Zhao X (2007) Microbial community structure of ethanol type fermentation in bio-hydrogen production. Environ Microbiol 9:1112-1125

11. Huang Y, Zong W, Yan X, Wang R, Hemme CL, Zhou J, Zhou Z (2010) Succession of the bacterial community and dynamics of hydrogen producers in a hydrogen-producing bioreactor. Appl Environ Microbiol 76:3387-3390

12. Quéméneur M, Hamelin J, Benomar S, Guidici-Orticoni MT, Latrille E, Steyer JP, Trably E (2011) Changes in hydrogenase genetic diversity and proteomic patterns in mixed-culture dark fermentation of mono-, di- and trisaccharides. Int J Hydrogen Energy 36:11654-11665

13. Pan CM, Fan YT, Xing Y, Hou HW, Zhang ML (2008) Statistical optimization of process parameters on biohydrogen production from glucose by Clostridium sp. Fanp2. Bioresour Technol 99:3146-3154

14. Signorini A, Massini G, Migliore G, Tosoni M, Varrone C, Izzo G (2008) Sediment biogeochemical differences in two pristine Mediterranean coastal lagoons (in Italy) characterized by different phanerogam dominance - a comparative approach. Mar Freshw Ecosyst 18(S1):S27-S44

15. Lahtinen SJ, Gueimonde M, Ouwehand AC, Reinikainen JP, Salminen SJ (2006) Comparison of four methods to enumerate probiotic bifidobacteria in a fermented food product. Food Microbiol 23:571-577 
16. Mills DK, Fitzgerald K, Litchfield CD, Gillevet PM (2003) A comparison of DNA profiling techniques for monitoring nutrient impact on microbial community composition during bioremediation of petroleum-contaminated soils. J Microbiol Methods 54:57-74

17. Thompson JD, GibsonTJ PF, Jeanmougin F, Higgins DG (1997) The ClustalX windows interface: flexible strategies for multiple sequence alignment aided by quality analysis tools. Nucl Ac Res 24:4876-4882

18. Abreu AA, Alves Jl, Pereira MA, Sousa DZ, Alves MM (2011) Strategies to suppress hydrogen-consuming microorganisms affects macro and micro scale structure and microbiology of granular sludge. Biotechnol Bioeng 108:1766-1775

19. Lin YH, Juan ML, Hsien HJ (2011) Effects of temperature and initial pH on biohydrogen production from food-processing wastewater using anaerobic mixed cultures. Biodegradation 22:551-563

20. Tiirola MA, Suvilampi JE, Kulomaa MS, Rintala JA (2003) Microbial diversity in a thermophilic aerobic biofilm process: analysis by length heterogeneity PCR (LH-PCR). Water Res 37:2259-2268

21. Gatti M, De Dea LJ, De Lorentiis A, Bottari B, Santarelli M, Bernini V, Neviani E (2008) Dynamics of whole and lysed bacterial cells during parmigianoreggiano cheese production and ripening. Appl Environ Microbiol 74:6161-6167

22. Entry JA, Mills DK, Mathee K, Jayachandran K, Sojka RE, Narasimhan G (2008) Influence of irrigated agriculture on soil microbial diversity. Appl Soil Ecol 40:146-154

23. Han SK, Kim SK, Shin HS (2005) UASB treatment of wastewater with VFA and alcohol generated during hydrogen fermentation of food waste. Proc Biochem 40:2897-2905

24. Ueno Y, Otsuka S, Morimoto M (1996) Hydrogen production from industrial wastewater by anaerobic microflora in chemostat culture. J Ferment Bioeng 82:194-197

25. Zhong WM, Yu R, Zhang P, Fan M, Zhou Z (2009) Efficient hydrogen gas production from cassava and food waste by a two-step process of dark fermentation and photo-fermentation. Biomass Bioen 33:1458-1463

doi:10.1186/2192-0567-3-3

Cite this article as: Di Bonito et al:: Characterization by length heterogeneity (LH)-PCR of a hydrogen-producing community obtained in dark fermentation using coastal lake sediment as an inoculum. Energy, Sustainability and Society 2013 3:3.

\section{Submit your manuscript to a SpringerOpen ${ }^{\circ}$ journal and benefit from:}

- Convenient online submission

- Rigorous peer review

- Immediate publication on acceptance

- Open access: articles freely available online

- High visibility within the field

- Retaining the copyright to your article

Submit your next manuscript at $\gg$ springeropen.com 